Western University

Scholarship@Western

Anatomy and Cell Biology Publications

Anatomy and Cell Biology Department

$4-2013$

\title{
Defining the Efficacy of Aortic Root Enlargement Procedures: A Comparative Analysis of Surgical Techniques
}

\author{
Katie L. Losenno \\ Western University \\ Jill J. Gelinas \\ Western University \\ Marjorie Johnson \\ Western University, Marjorie.johnson@schulich.uwo.ca \\ Michael W. A. Chu \\ Western University, Michael.Chu@lhsc.on.ca
}

Follow this and additional works at: https://ir.lib.uwo.ca/anatomypub

Part of the Anatomy Commons, and the Cell and Developmental Biology Commons

Citation of this paper:

Losenno, Katie L.; Gelinas, Jill J.; Johnson, Marjorie; and Chu, Michael W. A., "Defining the Efficacy of Aortic Root Enlargement Procedures: A Comparative Analysis of Surgical Techniques" (2013). Anatomy and Cell Biology Publications. 88.

https://ir.lib.uwo.ca/anatomypub/88 


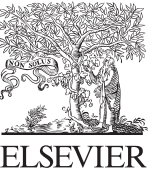

\title{
Clinical Research
}

\section{Defining the Efficacy of Aortic Root Enlargement Procedures: A Comparative Analysis of Surgical Techniques}

\author{
Katie L. Losenno, BSc, ${ }^{a}$ Jill J. Gelinas, MD, FRCSC, ${ }^{b}$ Marjorie Johnson, PhD, ${ }^{a}$ and \\ Michael W.A. Chu, MD, FRCSC ${ }^{a, b}$ \\ a Department of Anatomy and Cell Biology, University of Western Ontario, London, Ontario, Canada \\ ${ }^{b}$ Division of Cardiac Surgery, Department of Surgery, Lawson Health Research Institute, University of Western Ontario, London, \\ Ontario, Canada
}

\begin{abstract}
Background: Aortic root enlargement (ARE) procedures are believed to allow implantation of larger valve prostheses; however, little evidence exists to support the specific efficacy of various techniques. Methods: Using a cadaveric model, 20 adult (72.4 \pm 15.3 years) hearts were stratified into $\mathbf{4}$ groups based on annular diameter: $<\mathbf{2 0}$ $\mathrm{mm}, 20-22 \mathrm{~mm}, 22-24 \mathrm{~mm}$, and $>24 \mathrm{~mm}$. Each heart underwent an aortic valve replacement following a Nicks, Manougian, aortoventriculoplasty and modified Bentall procedure, with appropriate reversals between procedures.

Results: All 4 groups experienced similar increases in annular diameter $(P=0.43)$ and prosthesis size implanted $(P=0.51)$ with each enlargement technique. The Nicks, Manougian, modified Bentall and aortoventriculoplasty procedures enlarged the annulus by $0.43 \pm 0.45$ $\mathrm{mm}, 3.63 \pm 0.95 \mathrm{~mm}, 0.78 \pm 0.65 \mathrm{~mm}$, and $6.08 \pm 1.19 \mathrm{~mm}$, respectively $(P<0.001)$. No significant change in prosthesis size was observed after the Nicks procedure $(P=$ not significant). Increases of $1.3 \pm 0.5,1.3 \pm 0.5$, and $2.7 \pm 0.6$ prosthesis sizes were achieved with the Manougian, modified Bentall and aortoventriculoplasty techniques respectively $(P<0.001)$.

Conclusions: ARE procedures appear equally efficacious in both small and larger aortic roots. Although all 4 ARE techniques increased the
\end{abstract}

The small aortic root remains a challenging problem in aortic valve surgery. Aortic valve replacement (AVR) improves patient survival and relieves symptoms; however in small aortic annuli, these benefits may be dependent on the surgeon's ability to implant a suitably sized prosthetic valve. ${ }^{1,2}$ Prosthesispatient mismatch (PPM) infers the clinical scenario where the

Received for publication February 20, 2012. Accepted April 11, 2012.

Corresponding author: Dr Michael W.A. Chu, Department of Surgery, B6-106 University Hospital, London Health Sciences Centre, 339 Windermere Road, PO Box 5339, London, Ontario N6A 5A5, Canada. Tel.: + 1519-663-3593; fax: + 1-519-663-3276.

E-mail: michael.chu@lhsc.on.ca

See page $\mathrm{xxx}$ for disclosure information.

\section{RÉSUMÉ}

Introduction : La dilatation de l'anneau aortique (DAA) permettrait l'implantation de plus grandes prothèses valvulaires. Cependant, peu de données appuyant l'efficacité spécifique des nombreuses techniques existent.

Méthodes : En utilisant un modèle cadavérique, 20 cœurs d'adultes (72,4 $\pm 15,3$ ans) ont été stratifiés en 4 groupes selon le diamètre annulaire : $<20 \mathrm{~mm}, \mathbf{2 0 - 2 2} \mathrm{mm}, 22-24 \mathrm{~mm}$ et $>24 \mathrm{~mm}$. Chaque cœur a subi un remplacement valvulaire aortique à la suite d'une intervention de Nicks, de Manougian, de Bentall modifiée et d'une aortoventriculoplastie, ainsi que les reconstitutions appropriées entre les interventions.

Résultats : Les 4 groupes ont connu des augmentations similaires du diamètre annulaire $(P=0,43)$ et de la taille de la prothèse implantée $(P=0,51)$ lors de chacune des techniques de dilatation. Les interventions de Nicks, de Manougian, de Bentall modifiée et l'aortoventriculoplastie ont permis de dilater l'anneau de 0,43 $\pm 0,45$ $\mathrm{mm}, 3,63 \pm 0,95 \mathrm{~mm}, 0,78 \pm 0,65 \mathrm{~mm}$ et de $6,08 \pm 1,19 \mathrm{~mm}$, respectivement $(P<0,001)$. Aucun changement significatif dans la taille de la prothèse n'a été observé après l'intervention de Nicks $(P=$ non significatif). Les augmentations de taille des prothèses de 1,3 \pm $0,5,1,3 \pm 0,5$ et $2,7 \pm 0,6$ ont été atteintes par les techniques de

effective orifice area of an implanted prosthetic valve is too small for the patient's body size ${ }^{1,3}$ and has been associated with residual left ventricular outflow tract obstruction, incomplete left ventricular mass regression, muted symptom relief, and increased early and late mortality. ${ }^{1,2,4-6}$ PPM is a modifiable condition and in some cases, surgical enlargement of the aortic root may be necessary. Commonly employed aortic root enlargement (ARE) techniques include posterior approaches proposed by Nicks et al. ${ }^{7}$ and Manougian and Seybold-Epting ${ }^{8}$, and more aggressive approaches including the modified Bentall $^{9}$ and aortoventriculoplasty ${ }^{10,11}$ procedures. These techniques are believed to increase the diameter of small aortic annuli to accept larger prosthetic valves with better hemody- 
annular diameter, only the Manougian, modified Bentall and aortoventriculoplasty procedures allowed for the implantation of a larger prosthetic valve. The Nicks procedure, which is likely the most commonly performed ARE, does not allow for the implantation of a larger prosthesis. Surgeon preference and patient factors may help in selecting the most appropriate ARE technique, as the modified Bentall and Manougian procedures achieved similar increases in valve size.

namic performance. Currently, there is no consensus on the effectiveness of each respective ARE technique.

Although these ARE procedures are well accepted and widely practiced with good outcomes, ${ }^{12,13}$ there is a paucity of data to support the commonly accepted valve size increases that are expected of each ARE technique. Furthermore, there is evidence to suggest that certain ARE procedures may be inadequate and leave patients with residual severe $\mathrm{PPM}^{14}$; signifying that perhaps the most appropriate techniques are not always being chosen. Therefore, the objective of this study was to provide comparative data to clarify the current beliefs concerning the upsizing of aortic valve prostheses attainable with the Nicks, Manougian, modified Bentall, and aortoventriculoplasty procedures.

\section{Methods}

We examined 34 adult hearts from formalin fixed cadaveric specimens and based on specimen size and quality of preservation, identified an optimal 20 specimens for use in this investigation. Mean age was $72.4 \pm 15.3(48-104)$ years and consisted of $12(60 \%)$ female and $8(40 \%)$ male donors. The study group was stratified by annular diameters into 4 groups: $<20 \mathrm{~mm}(\mathrm{n}=5), 20-22 \mathrm{~mm}(\mathrm{n}=5), 22-24 \mathrm{~mm}$ $(\mathrm{n}=5)$, and $>24 \mathrm{~mm}(\mathrm{n}=5)$ and the study protocol was performed on each heart specimen $(\mathrm{N}=20)$. After excision of the native aortic valve cusps, the aortic annulus was measured and a bileaflet mechanical prosthesis was implanted to determine the baseline prosthesis size. Each heart then underwent all 4 ARE procedures in the following order: Nicks, Manougian, aortoventriculoplasty, and the modified Bentall procedure. After each enlargement, the pericardial patch was removed and the incision lines were reapproximated, exercising great care to return the root to its original size. To ensure that reapproximations could be performed without significantly altering the annular diameter, interprocedural measurements were performed in an additional subset $(\mathrm{n}=$ 3) of hearts. All surgical procedures were performed by an experienced cardiothoracic surgeon (M.W.A.C.). Approval for this research was granted by the Cadaveric Ethics Committee at the University of Western Ontario.

\section{Measurement techniques}

The annular diameter was measured from the nadir of the left coronary sinus directly across to the right noninterleaflet triangle. The diameter was measured in the native root and
Manougian, de Bentall modifiée et de l'aortoventriculoplastie, respectivement $(P<0,001)$.

Conclusions : Les interventions pour la DAA semblent également efficaces pour les petits et les plus grands anneaux aortiques. Même si les 4 techniques de DAA ont augmenté le diamètre annulaire, seules les interventions de Manougian, de Bentall modifiée et l'aortoventriculoplastie ont permis l'implantation d'une plus grande prothèse valvulaire. L'intervention de Nicks, qui est susceptible d'être la DAA la plus communément réalisée, ne permet pas l'implantation d'une prothèse plus large. La préférence du chirurgien et les facteurs du patient peuvent aider à choisir la technique de DAA la plus appropriée puisque les interventions de Bentall modifiée et de Manougian ont atteint des augmentations similaires de la taille de la valve.

again after all 4 root enlargement procedures. Measurements were made 3 times to the nearest $0.01 \mathrm{~mm}$ using a digital vernier caliper.

\section{Surgical techniques}

The root enlargement techniques were performed according to the original descriptions by Manougian and Seybold-Epting, ${ }^{8}$ Bentall and De Bono, ${ }^{9}$ Konno et al., ${ }^{10}$ and Rastan and Koncz. ${ }^{11}$ A modification of the Nicks procedure was used whereby the posterior commissure was resected and the patch enlargement was carried down to the origin of the anterior leaflet of the mitral valve (Fig. 1A) as described by Nunez et al. ${ }^{15}$ The Manougian enlargement was performed as an extension of the previous Nicks procedure carrying the patch through the aortic annulus and halfway toward the free edge of the anterior leaflet of the mitral valve (Fig. 1A, Fig. 2). The aortoventriculoplasty was performed by making an incision through the wall of the right coronary sinus and was carried through into the muscular interventricular septum being careful to avoid the first septal perforator artery (Fig. 1B). The interventricular septum and right ventricular free wall were closed with separate patches. The modified Bentall procedure was performed after excision of the aortic sinuses and development of the coronary buttons (Fig. 1C). The valved conduit was implanted using a supra-annular technique. In all procedures, we attempted to implant the largest acceptable valve size possible, without overstretching or distorting the aortic root. With the exception of the modified Bentall technique, all valves were sewn in line with the native aortic annulus.

\section{Statistical analysis}

Data were imported and analyzed using SPSS software version 18 (SPSS Inc, Chicago, IL). Continuous data are presented as mean $\pm \mathrm{SD}$. A general linear model repeated measures analysis of variance (ANOVA) was performed to test for interaction effects between the 4 groups. All combinations of the 4 different techniques were compared using paired $t$ tests. To compare specific pairs, the Bonferroni correction was used to ensure that the familywise type 1 error was less than $5 \%(P<0.05)$. Due to the use of the Bonferroni correction, $P$ values $<0.005$ were considered significant at the $95 \%$ confidence interval. Both diameter and prosthesis sizes were considered continuous variables. 

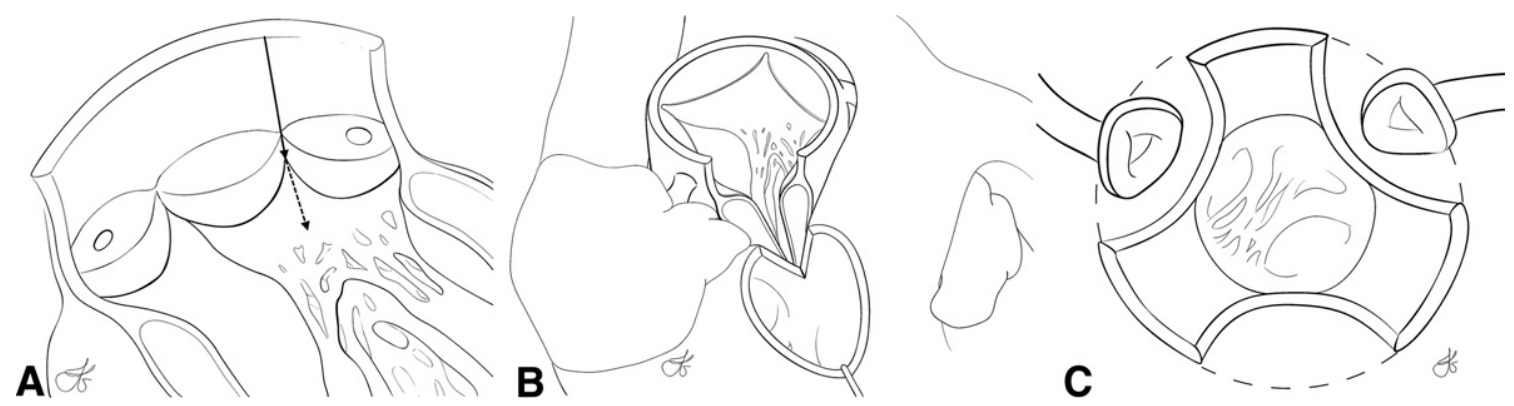

Figure 1. Schematic drawings of aortic root enlargement procedures. (A) Nicks and Manougian procedures. We performed the Nicks procedure by enlarging the posterior aortic root toward the aortic annulus at the posterior commissure (solid line). We performed the Manougian technique as an extension of the previous incision through the aortic annulus midway down the anterior leaflet of the aortic valve (dashed line). (B) Aortoventriculoplasty. The incision was carried through the wall of the right coronary sinus and into the muscular interventricular septum. The free wall of the right ventricle was also opened, exposing the interventricular septum from the anterior aspect. (C) Modified Bentall procedure. The sinuses of Valsalva were excised and the coronary buttons were prepared. The valved conduit was then implanted using a supra-annular technique.

\section{Results}

\section{ARE effect on different sized aortic roots}

There was no statistically significant difference in the effect of the ARE on different sized aortic roots as all 4 groups experienced similar increases in annular diameter $(P=0.43)$ and prosthesis size implanted $(P=0.51)$ with each technique performed. Because the null hypothesis was not rejected, the data were collapsed and analyzed as 1 group $(\mathrm{N}=20)$.

\section{Annular diameter enlargement and acceptable valve sizes implanted}

The baseline diameter of the aortic annuli ranged from $17.02 \mathrm{~mm}$ to $24.80 \mathrm{~mm}$ with a mean of $21.79 \pm 2.46 \mathrm{~mm}$. The Nicks, Manougian, modified Bentall, and aortoventriculoplasty procedures enlarged the annulus by $0.43 \pm 0.45 \mathrm{~mm}$, $3.63 \pm 0.95 \mathrm{~mm}, 0.78 \pm 0.65 \mathrm{~mm}$, and $6.08 \pm 1.19 \mathrm{~mm}$, respectively $(P<0.001)$ compared with the initial diameter.

Baseline prosthesis sizes ranged from 17 to 23 with a mean of $20.5 \pm 1.1$.

In 16 of 20 hearts $(80 \%)$, the Nicks procedure failed to allow for the implantation of a larger valve than in the native root $(P=0.042$; not significant due to Bonferroni correction). An increase of $1.3 \pm 0.5,1.3 \pm 0.5$, and $2.7 \pm 0.6$ prosthesis sizes were achieved with the Manougian, modified Bentall, and aortoventriculoplasty techniques respec- tively $(P<0.001)$. Mean prosthesis sizes implanted, aortic annular diameters in the native root, and aortic annular diameters after each ARE procedure are shown in Figure 3. The Manougian, modified Bentall, and aortoventriculoplasty procedures always allowed for an increase in at least 1 valve size with respect to the initial prosthesis size. The frequency and specific increases in prosthesis size after each ARE technique are shown in Table 1.

As demonstrated in Table 2 , significant differences in annular diameter were found between all pairings $(P<0.001)$ except for the Nicks-modified Bentall comparison $(P=0.01$, not significant due to Bonferroni correction). Implanted aortic valve prosthesis size was different in all pairings $(P<0.001)$ with the exception of the initial Nicks comparison $(P=0.042$, not significant due to Bonferroni correction) and the Manougian-modified Bentall comparison $(P=1)$.

Variations in the annular diameter after reapproximations were small, ranging from $-0.06 \mathrm{~mm}$ to $0.21 \mathrm{~mm}$ and none were significant (Table 3). Furthermore, there were no changes in the largest implantable prosthesis size after performing the reapproximations.

\section{Discussion}

Optimal surgical management of the small aortic root remains controversial. ARE procedures are generally employed to address more significant PPM; however, there is certainly no
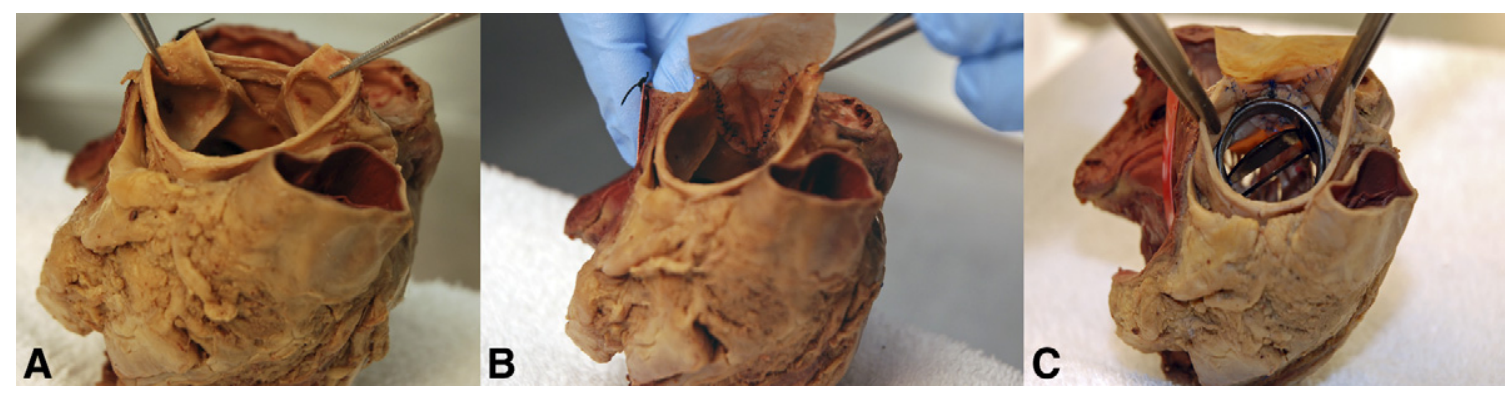

Figure 2. Photograph demonstrating the Manougian technique. (A) The incision was made through the posterior commissure and carried halfway toward the free edge of the anterior leaflet of the mitral valve. (B) A pericardial patch was sewn into the root using a running continuous technique. (C) The mechanical prosthesis was implanted into the enlarged aortic root. 


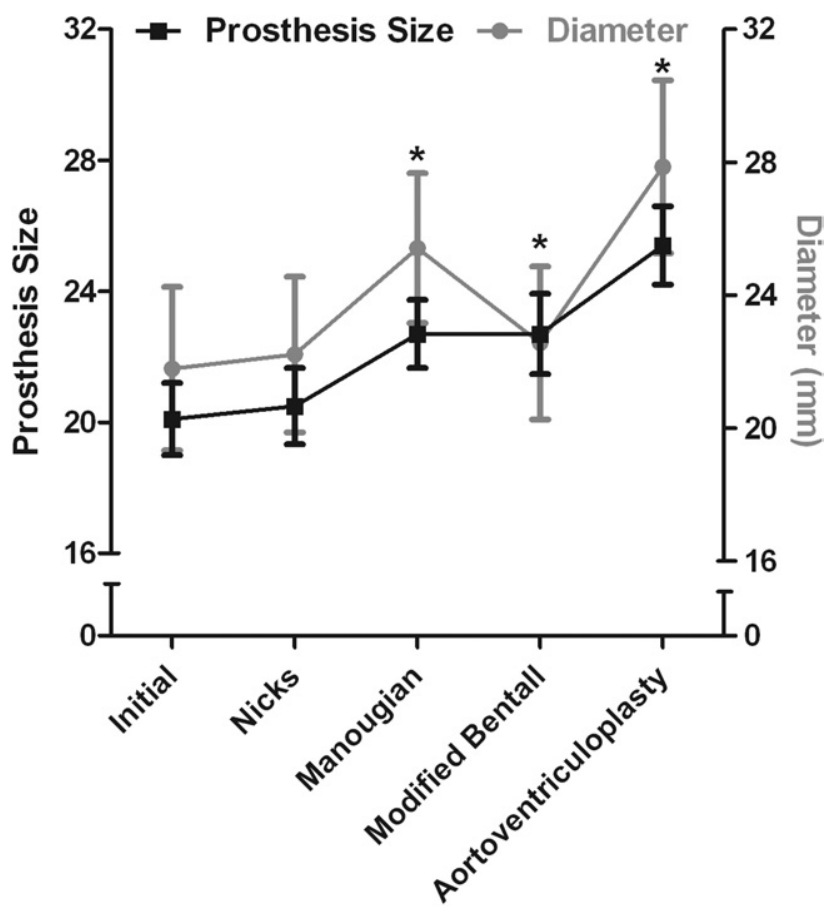

Root Enlargement Technique

Figure 3. Mean annular diameter and implanted valve prosthesis sizes in the native aortic root and after all 4 aortic root enlargement (ARE) techniques (mean $\pm \mathrm{SD} ; \mathrm{n}=20$ ). * Significant increase in implanted prosthesis size $(P<0.001)$ with respect to the native aortic root.

consensus on the appropriateness of each technique. Simpler techniques are believed to have only limited effectiveness on annular enlargement but likely do not increase perioperative risks. More aggressive techniques are commonly believed to enlarge the aortic root significantly, but early published results suggested an increase in mortality when performing root enlargement procedures. ${ }^{16}$ Conversely, more recent data would suggest that ARE procedures do not add perioperative risk and are safe in experienced hands. ${ }^{12,13}$ Though some groups choose to perform routine enlargement of the small aortic root, there is limited evidence to support the specific efficacy of the most commonly employed ARE procedures, as all techniques are not equal. In addition, it appears that the most appropriate ARE techniques may not always be chosen for each patient, thus, leaving some patients with severe PPM and increased late mortality despite pericardial patch root enlargements. ${ }^{14}$
Posterior annular enlargement techniques described by Nicks et al. ${ }^{7}$ and Manougian and Seybold-Epting ${ }^{8}$ are commonly thought to increase the size of the aortic root sufficiently to allow for the upsizing of the aortic valve prosthesis by 1 or 2 sizes respectively over what the native annulus would have accepted. $^{12,17,18}$ In the modified Bentall procedure, ${ }^{9}$ supra-annular seating of the valved conduit allows the implantation of an oversized prosthesis; however, the extent and limitations of oversizing with this technique are not well described. ${ }^{19,20}$ Aortoventriculoplasty as described by Konno et al. ${ }^{10}$ and Rastan and $\mathrm{Koncz}^{11}$ is purported to allow for upsizing of the aortic valve prosthesis by as much as 3 sizes. ${ }^{21}$ Our investigation quantifies the specific efficacy of the 4 most commonly used ARE procedures; information we believe is valuable for guiding preoperative and intraoperative decision making in patients with a small aortic annuli.

Though the Nicks procedure ${ }^{7}$ is likely the most commonly performed ARE because of its simplicity and low morbidity, our results suggest that this technique is ineffective with respect to preventing PPM as it only increased annular diameter by an average of $0.43 \pm 0.45 \mathrm{~mm}(P<0.001)$ and allowed for the implantation of a larger prosthetic aortic valve in only $20 \%$ of the study population. Our results were inconsistent with a previous report by Nakano and colleagues that described a comparatively 10 -fold larger annular increase following the Nicks procedure in 33 patients. ${ }^{22}$ They did not describe how they measured the aortic annulus in their investigation, nor did they have a control arm to compare the efficacy of the enlargement. While it may be possible to implant a valve 1 size larger using a combination of the Nicks enlargement and oblique implantation of the prosthesis, ${ }^{18}$ recent studies have revealed that the hemodynamic advantages of implanting a larger mechanical valve prosthesis is diminished when the prosthesis is implanted in a moderately tilted position. ${ }^{23}$ As such, we choose to implant a larger prosthesis only if it can be inserted with minimal tilting. Furthermore, though this technique may be used to pass a larger prosthesis through a small sinotubular junction, the implantable prosthesis size should be determined by the annular diameter, and not the sinotubular junction. That being said, the Nicks procedure may be indicated in patients with restriction of the sinotubular junction and poor aortic compliance so long as the annulus can accommodate an adequately sized aortic valve prosthesis and PPM is not a concern.

ARE as proposed by Manougian and Seybold-Epting ${ }^{8}$ is more technically demanding than the Nicks procedure, but it appears to reproducibly widen the annulus and allow for the implantation of a larger aortic valve prosthesis. Sankar and colleagues ${ }^{17}$ reported their experience using the Manougian technique in a group of 17 patients, wherein they were able to

Table 1. Increase in implanted prosthetic valve size attainable with each ARE technique

Increase in implanted prosthetic valve size

\begin{tabular}{lccccc} 
ARE technique & No change & +1 & +2 & +3 & +4 \\
\hline Nicks $(\mathrm{n}=20)$ & $16(80 \%)$ & $4(20 \%)$ & - & - & - \\
Manougian $(\mathrm{n}=20)$ & - & $14(70 \%)$ & $6(30 \%)$ & - & - \\
Modified Bentall $(\mathrm{n}=20)$ & - & $14(70 \%)$ & $6(30 \%)$ & - & - \\
Aortoventriculoplasty $(\mathrm{n}=20)$ & - & - & $8(40 \%)$ & $11(55 \%)$ & $1(5 \%)$ \\
\hline
\end{tabular}

ARE, aortic root enlargement.

* Not significant due to Bonferroni correction. 
Table 2. Results of paired $t$ test for differences in diameter and prosthesis size $(n=20)$

\begin{tabular}{|c|c|c|c|c|}
\hline Pair & $\begin{array}{l}\text { Increase in diameter } \\
(\mathrm{mm} \pm \mathrm{SD})\end{array}$ & $P$ value & $\begin{array}{c}\text { Increase in prosthesis } \\
\text { size } \pm S D\end{array}$ & $P$ value \\
\hline Initial - Nicks & $0.43 \pm 0.45$ & $<0.001$ & $0.2 \pm 0.4$ & $0.042^{*}$ \\
\hline Initial - Manougian & $3.63 \pm 0.95$ & $<0.001$ & $1.3 \pm 0.5$ & $<0.001$ \\
\hline Initial - Bentall & $0.78 \pm 0.65$ & $<0.001$ & $1.3 \pm 0.5$ & $<0.001$ \\
\hline Initial - aortoventriculoplasty & $6.08 \pm 1.19$ & $<0.001$ & $2.7 \pm 0.6$ & $<0.001$ \\
\hline Nicks - Manougian & $3.19 \pm 0.96$ & $<0.001$ & $1.1 \pm 0.6$ & $<0.001$ \\
\hline Nicks - Bentall & $0.35 \pm 0.54$ & $0.01^{\dagger}$ & $1.1 \pm 0.6$ & $<0.001$ \\
\hline Nicks - aortoventriculoplasty & $5.65 \pm 1.24$ & $<0.001$ & $2.5 \pm 0.6$ & $<0.001$ \\
\hline Bentall - Manougian & $2.85 \pm 0.75$ & $<0.001$ & $0.0 \pm 0.6$ & 1 \\
\hline Manougian - aortoventriculoplasty & $2.46 \pm 1.02$ & $<0.001$ & $1.4 \pm 0.5$ & $<0.001$ \\
\hline Bentall - aortoventriculoplasty & $5.31 \pm 1.04$ & $<0.001$ & $1.4 \pm 0.7$ & $<0.001$ \\
\hline
\end{tabular}

* Not significant due to Bonferroni correction.

${ }^{\dagger}$ Not significant due to Bonferroni correction.

enlarge the annulus by 4 to $6 \mathrm{~mm}$. In our series, we were able to enlarge the annulus by an average of $3.63 \pm 0.95 \mathrm{~mm}(P<$ 0.001 ) following the Manougian procedure. In all cases, this was sufficient to allow for upsizing of the aortic valve by at least 1 size (70\%, 1 size; $30 \%, 2$ sizes). When PPM is predicted, the Manougian technique could be considered to facilitate implantation of a larger aortic valve prosthesis by 1 or 2 sizes without requiring significant tilting during implantation. Although the patch enlargement was performed to the midportion of the anterior leaflet of the mitral valve, some hearts experienced an increase in 1 prosthesis size while others experienced an increase of 2 sizes. These differences occurred in all groups, regardless of initial annular diameter and implanted prosthesis size. It is possible that variation in the height of the interleaflet triangles and the anterior leaflet of the mitral valve may be a factor in the amount of enlargement possible using the Manougian technique. Further investigation may help to determine a prediction model of the increase in prosthesis size based on anatomical dimensions.

Although the modified Bentall procedure was originally described for aneurysmal disease, it has gained recent application in patients with small aortic annuli. Tabata and colleagues recommend the implantation of a valve conduit 1 size larger than the native annulus can accommodate, ${ }^{19}$ whereas Urbanski's group chooses a standard prosthesis size based on sex. ${ }^{20}$ When performing the modified Bentall procedure, we prefer to only implant a prosthesis size which can be reasonably accommodated within the root in order to avoid overstretching, distortion, and altered hemodynamic performance of the prosthesis. In our series, we were able to consistently implant an aortic

Table 3. Effect of reapproximations on annular diameter and prosthesis size

\begin{tabular}{|c|c|c|c|c|}
\hline Reapproximation & $\begin{array}{c}\text { Difference } \\
\text { in annular } \\
\text { diameter }(\mathrm{mm})\end{array}$ & $P$ value & $\begin{array}{l}\text { Difference in } \\
\text { prosthesis } \\
\text { size }\end{array}$ & $P$ value \\
\hline Initial - post Nicks & -0.06 & 0.58 & 0 & 1 \\
\hline Initial - post Manougian & 0.01 & 0.96 & 0 & 1 \\
\hline $\begin{array}{l}\text { Initial - post } \\
\text { aortoventriculoplasty }\end{array}$ & 0.15 & 0.08 & 0 & 1 \\
\hline Post Nicks - post & & & & \\
\hline $\begin{array}{c}\text { Manougian } \\
\text { Post Nicks - post }\end{array}$ & 0.07 & 0.66 & 0 & 1 \\
\hline $\begin{array}{l}\text { aortoventriculoplasty } \\
\text { Post Manougian - post }\end{array}$ & 0.21 & 0.18 & 0 & 1 \\
\hline aortoventriculoplasty & 0.14 & 0.21 & 0 & 1 \\
\hline
\end{tabular}

valve prosthesis at least 1 size larger than the native annulus would accept (70\%, 1 size; 30\%, 2 sizes) using the modified Bentall procedure. Though this procedure maybe employed to facilitate the implantation of a larger aortic valve prosthesis, it does not directly address the aortic annulus but rather allows for the larger prosthesis to be implanted in a supra-annular position. This was confirmed in our series because we were able to implant a valve 1 size larger with the modified Bentall procedure (supra-annular position) compared with the Nicks procedure, despite having similar aortic annular diameter measurements. Interestingly, both the Manougian and the modified Bentall procedures resulted in a similar increase in the size of aortic valves subsequently implanted. The ability of these procedures to allow for similar oversizing in aortic valve prostheses has yet to be described in the literature, but does suggest that the surgeon can select whichever approach they feel is most appropriate for their patient with similar results. Furthermore, the modified Bentall provides another surgical option in elderly patients at risk for PPM who also have poor aortic compliance whereas the use of the Manougian technique may be more appropriate in younger patients with good aortic compliance.

The groups of Konno and colleagues ${ }^{10}$ and Rastan and Koncz $^{11}$ originally reported an anterior aortoventriculoplasty for the management of tunnel subaortic stenosis. This procedure has been most commonly performed in conjunction with a pulmonary homograft in a pediatric or young adult population for the treatment of congenital aortic stenosis ${ }^{24}$ and more recently for the treatment of complex left ventricular outflow tract obstruction, especially in those with a small aortic root. ${ }^{25}$ Aortoventriculoplasty is technically demanding, requiring patch closure of both the interventricular septum and the right ventricle and care must be taken to avoid injury to the first septal perforating artery and the conduction system. Cobanoglu and colleagues have reported a $40 \%$ to $50 \%$ enlargement of the annulus following the Konno ARE. ${ }^{25}$ In our study, we were able to enlarge the aortic annulus by an average of $6.08 \pm 1.19$ $\mathrm{mm}(P<0.001)$ with an anterior aortoventriculoplasty. This translated into the implantation of a larger aortic valve prosthesis by 2 to 4 sizes (40\%, 2 sizes; 55\%, 3 sizes; 5\%, 4 sizes). The aortoventriculoplasty was the most efficacious technique evaluated in our study; however, as a result of the complexity and associated risks, this procedure should be reserved for patients in whom more conservative root enlargement techniques have failed to relieve severe PPM. 
There are several important strengths to our investigation. The use of cadaveric specimens allowed us to perform multiple ARE techniques on the same aortic root such that each heart served as its own control, eliminating anatomical variation as a possible confounding factor. The cadaveric model also made it possible to implant the same prosthesis type in all specimens. Performing multiple unnecessary procedures is not ethically possible in a live patient population; however, a randomized trial investigating various ARE techniques would be difficult to perform because of the large number of patients required and many inherent complexities in a trial of that design. Therefore the cadaveric model is a good alternative and provides valuable comparative data without increasing patient risks. Moreover, apart from simply determining the increase in implanted prosthesis size, our study also evaluated the increase in annular diameter from the various ARE techniques, allowing this information to be extrapolated to different valve prostheses. There are few published studies evaluating detailed increases in aortic annular diameters and implantable prosthesis sizes possible with the commonly performed ARE techniques, and none providing a comparative analysis of the efficacy of these techniques.

Our study had a number of limitations. (1) It is likely that the formalin fixed aortic tissue was less flexible than that of live tissue and as such, the efficacy of the reported techniques may be somewhat conservative. Nevertheless, ARE is often contemplated in elderly patients with heavily calcified native aortic valves and noncompliant aortic roots. Although fresh hearts would be ideal for use in this investigation, we believe that the formalin fixation was uniform throughout all specimens. (2) Unfortunately, the use of a cadaveric model precluded any hemodynamic evaluation of pressure gradients and effective orifice area, both of which are important considerations when evaluating the outcomes of ARE surgery. (3) Our study necessitated repeated manipulation of the aortic roots, which is certainly artificial, in order to test the efficacy of the different ARE techniques. It is possible that this manipulation had a slight inadvertent effect on the diameter of the aortic annulus, however, interprocedural measurements assured us that this was less likely.

This study presents important comparative data identifying the specific efficacies of 4 commonly employed ARE techniques. We have demonstrated that although all 4 enlargement techniques result in an increase in annular diameter, only the Manougian, modified Bentall, and aortoventriculoplasty procedures allow for the implantation of a larger aortic valve prosthesis. These findings suggest that surgeon preference and patient factors may help in selecting the most appropriate ARE technique for patients with small aortic annuli requiring AVR.

\section{Acknowledgements}

The authors thank Yves Bureau, PhD, for his assistance with the statistical analysis. The mechanical bileaflet valves were given as an unrestricted, in kind donation from St Jude Medical.

\section{Disclosures}

The authors have no conflicts of interest to disclose.

\section{References}

1. Pibarot P, Dumesnil JG, Lemieux M, Cartier P, Metras J, Durand LG. Impact of prosthesis-patient mismatch on heamodynamic and symptom- atic status, morbidity and mortality after aortic valve replacement with a bioprosthetic heart valve. J Heart Valve Dis 1998;7:211-8.

2. Rao V, Jamieson WR, Ivanov J, Armstrong S, David TE. Prosthesispatient mismatch affects survival after aortic valve replacement. Circulation 2007;102:III5-9.

3. Rahimtoola $S$. The problem of valve prosthesis-patient mismatch. Circulation 1978;58:20-4.

4. Blais C, Dumesnil JG, Baillot R, Simard S, Doyle D, Pibarot P. Impact of valve prosthesis-patient mismatch on short-term mortality after aortic valve replacement. Circulation 2003;108:983-8.

5. Tasca G, Brunelli F, Cirillo M, et al. Impact of valve prosthesis-patient mismatch on left ventricular mass regression following aortic valve replacement. Ann Thorac Surg 2005;79:505-10.

6. Kohsaka S, Mohan S, Virani S, et al. Prosthesis-patient mismatch affects long-term survival after mechanical valve replacement. J Thorac Cardiovasc Surg 2008;135:1076-80.

7. Nicks R, Cartmill T, Bernstein L. Hypoplasia of the aortic root. The problem of aortic valve replacement. Thorax 1970;25:339-46.

8. Manougian S, Seybold-Epting W. Patch enlargement of the aortic valve ring by extending the aortic incision into the anterior mitral leaflet. J Thorac Cardiovasc Surg 1979;78:402-12.

9. Bentall $\mathrm{H}$, De Bono A. A technique for complete replacement of the ascending aorta. Thorax 1968;23:338-9.

10. Konno S, Imai Y, Iida Y, Nakajima M, Tatsuno K. A new method for prosthetic valve replacement in congenital aortic stenosis associated with hypoplasia of the aortic valve ring. J Thorac Cardiovasc Surg 1975;70: 909-17.

11. Rastan H, Koncz J. Aortoventriculoplasty. A new technique for the treatment of left ventricular outflow tract obstruction. J Thorac Cardiovasc Surg 1976;71:920-7.

12. Castro LJ, Arcidi JM Jr, Fisher AL, Gaudiani VA. Routine enlargement of the small aortic root: a preventive strategy to minimize mismatch. Ann Thorac Surg 2002;74:31-6.

13. Peterson MD, Borger MA, Feindel CM, David TE. Aortic annular enlargement during aortic valve replacement: improving results with time. Ann Thorac Surg 2007;83:2044-9.

14. Mohty-Echahidi D, Malouf JF, Girard SE, et al. Impact of prosthesis-patient mismatch on long-term survival in patients with small St Jude Medical mechanical prostheses in the aortic position. Circulation 2006;113:420-6.

15. Nunez L, Aguado MG, Pinto AG, et al. Enlargement of the aortic annulus by resecting the commissure between the left and noncoronary cusps. Tex Heart Inst J 1983;10:301-3.

16. Sommers KE, David TE. Aortic valve replacement with patch enlargement of the aortic annulus. Ann Thorac Surg 1997;63:1608-12.

17. Sankar NM, Rajan S, Singh RKK, Cherian KM. Enlargement of small aortic annulus by modified Manouguian's technique. Asian Cardiovasc Thorac Ann 1999;7:282-6.

18. Kinsley RH, Antunes MJ, McKibbin JK. Enlargement of the narrow aortic root and oblique insertion of a St Jude prosthesis. Br Heart J 1983;50:330-2.

19. Tabata M, Takayama H, Bowdish ME, Smith CR, Stewart AS. Modified Bentall operation with bioprosthetic valved conduit: Columbia University experience. Ann Thorac Surg 2009;87:1969-70.

20. Urbanski PP, Heinz N, Zhan X, Hijazi H, Zacher M, Diegeler A. Modified bio-Bentall procedure: 10-year experience. Eur J Cardiothorac Surg 2010;37:1317-21. 
21. Erez E, Tam VK, Williams WH, Kanter KR. The Konno aortoventriculoplasty for repeat aortic valve replacement. Eur J Cardiothorac Surg 2001;19:793-6.

22. Nakano S, Matsuda H, Shimazaki Y, et al. An appraisal of patch enlargement of the small aortic annulus in 33 patients undergoing aortic valve replacement. Eur J Cardiothorac Surg 1992;6:347-9.

23. Hartrumpf M, Albes JM, Krempl T, Rudolph V, Wahlers T. The hemodynamic performance of standard bileaflet valves is impaired by a tilted implantation position. Eur J Cardiothorac Surg 2003;23: 283-91.

24. Reddy VM, Rajasinghe HA, Teitel DF, Haas GS, Hanley FL. Aortoventriculoplasty with the pulmonary autograft: the "Ross-Konno" procedure. J Thorac Cardiovasc Surg 1996;111:158-65.

25. Cobanoglu A, Thyagarajan GK, Dobbs J. Konno-aortoventriculoplasty with mechanical prosthesis in dealing with small aortic root: a good surgical option. Eur J Cardiothorac Surg 1997;12:766-70. 